\title{
ENTRE LA HISTORIA DE LA MARGINALIDAD, LA HISTORIA DE LO IMAGINARIO Y LA PSICOHISTORIA: EL OCÉANO ÍNDICO EN LOS SIGLOS XIII A XV.
}

\author{
Fernando Rosas Moscoso \\ Universidad Ricardo Palma \\ frosas18@yahoo.com.ar
}

\section{RESUMEN}

Las relaciones entre la Historia y la Psicología se reflejan en algunas tendencias actuales de investigación histórica. La visión que se tenía del Océano Índico entre los siglos XIII al XV, a través de mapas antiguos, algunos viajeros y referencias fantásticas, genera el despliegue de mecanismos oníricos en donde lo maravilloso y lo monstruoso reflejan temores que también están vinculados a los profundos cambios que genera la transición del Feudalismo al Capitalismo. Finalmente, la realidad se impone a la fantasía, replegándose los sueños y temores a raíz del viaje a la India de Vasco da Gama (1498-1499).

\section{PALABRAS CLAVE}

Océano Índico (siglos XIII-XV) / Psicohistoria / Maravillas / Monstruos / Vasco de Gama.

\section{ABSTRACT}

The relationship between history and psychology reflect on current trends of historical research. The vision that had the Indian Ocean between the thirteenth and fifteenth centuries, through old maps, some travelers and fantastic references, generates the deployment of oniric mechanisms where the marvelous and the monstrous reflect fears that are also linked to the profound changes generated by the transition from Feudalism to Capitalism. Finally, reality imposes itself to fantasy, dreams and fears, falling back following the journey to India of Vasco de Gama (1498-1499).

\section{KEYWORDS}

Indian Ocean ( XIIIth - XVth centuries) / Psychohistory / Wonders / Monsters / Vasco da Gama. 


\section{A MANERA DE INTRODUCCIÓN.}

Hace unos 45 años comenzaban a desarrollarse nuevas tendencias de investigación histórica, algunas recogían la obra de precursores que incluso se remontaban al siglo XIX. Su evolución fue variable pero fueron consolidándose con la presencia de numerosas publicaciones que incluso alcanzaron a circular en contextos no académicos y a convertirse en best sellers nacionales. En el Perú su difusión fue extraordinariamente limitada e incluso recién han ingresado a la estructura curricular de las pocas universidades que ofrecen la especialidad; cabe resaltar que en la temprana y negativa eliminación de la especialidad de Historia en la Universidad de Lima, a mitad de los noventa, se habían incluido cursos como Historia de la Mentalidades, Historia Climática y otros. En nuestro medio académico, se puede verificar fácilmente que no se conoce la naturaleza de estas ya no nuevas tendencias, con lo que se deja de estimular la existencia de investigaciones y por ende se genera una ausencia de publicaciones.

En contacto temprano con la formación académica y la producción bibliográfica europea tratamos de estimular la reflexión en esos campos, promoviendo conferencias, seminarios y encuentros internacionales, que finalmente se concretó en el currículo de la especialidad de Historia de la Universidad de Lima. En esa línea en el año 1988 se publicó un trabajo, hoy agotado y olvidado, que tomó como centro de reflexión a la imagen del Océano Índico a fines de la Edad Media, bajo el estímulo intelectual del artículo de Jacques Le Goff L'Occident médiéval et l'Ocean Indien: un horizon onirique (París, 1970). Hemos querido, 27 años después, reproducir gran parte de ese aporte, con algunas modificaciones que una bibliografía actualizada consolida.

Cabe resaltar que esa mirada al océano Índico reunió perspectivas planteadas por tres nuevas tendencias de análisis histórico que ya se habían definido claramente en esos años: la historia de la marginalidad, la historia de lo imaginario y la psicohistoria. En el caso de la historia de la marginalidad, uno de los aspectos que aborda se refiere a la marginalidad espacial, que estaría vinculada a los espacios desconocidos de carácter geográfico o incluso de contextos específicos que por circunstancias variadas no quedan involucrados en el espacio pertinente a una sociedad concreta. Así, el Océano Índico para el occidente europeo entre los siglos XIII y XV era un espacio geográfico marginal, del cual se tenía algunas noticias pero que por la distancia y por el carácter misterioso que tenía, era entendido como parte 
de un mundo desconocido que encerraba grandes prodigios o desafiantes peligros. En los términos de la historia de lo imaginario, los espacios desconocidos o poco conocidos siempre albergan maravillas o terribles manifestaciones de la naturaleza, aquel imaginario de hoy se entendía como una realidad plena y contundente; así, los monstruos y todas las expresiones de una naturaleza trastocada podían ser descritos con lujo de detalles o representados en una iconografía compleja que iba desde mapas, pinturas, esculturas y otras expresiones. Por otra parte, la psicohistoria tiene un terreno fértil en contextos de marginalidad e imaginario, pues las expresiones concretas, a partir de informes de viajeros, interpretaciones bíblicas o del rico bestiario inherente, generan temores, inquietudes, frustraciones y aproximan al hombre a un mundo de ensueño o pesadilla, expresado en complejos mecanismos oníricos que buscan compensar las limitaciones que le imponen la falta del conocimiento, la distancia o las ciertas o falsas referencias que escasamente se refieren a esos espacios; la psicología aporta al historiador una serie de instrumentos de análisis que posibilitan una explicación válida a complejos y extraños procesos que la naturaleza de la psique humana alcanza a generar; en esa conexión entre la psicología y la historia destaca la proximidad del psicoanálisis.

Estas tendencias de análisis histórico, que convergen en un espacio concreto y en una época determinada, obligan a una visión multidisciplinaria en donde varias ciencias humanas se pueden unir para enriquecer el conocimiento de la sociedad de ese tiempo. Por otra parte, se debe tener en cuenta también que en esos siglos empieza a consolidarse el sistema capitalista en su fase comercial, lo cual exacerba tensiones y crea interrogantes o descubre realidades conforme se va llegando a fines del siglo XV, cuando se abren las puertas de los nuevos mundos a los grandes navegantes y descubridores. No debemos olvidar tampoco, que en esa etapa final el Humanismo y el Renacimiento han quedado comprometidos, no solo en los escenarios económico, social y político, sino también en las estructuras mentales. Tanto Vasco Da Gama, en el escenario índico como Colón, en el escenario atlántico, son los encargados de develar misterios o generar maravillas, en todo caso, el mundo a partir del siglo XVI no será el mismo y el Océano Índico, por lo tanto, tampoco.

\section{LA GEOGRAFÍA DE LO CONOCIDO Y LO ESCONOCIDO}

Durante los siglos comprendidos entre la desintegración del Imperio Romano y el apogeo del sistema del sistema feudal, los conocimientos 
geográficos fueron olvidándose o subordinándose a los cánones bíblicos (Samarkin, 1981, p. 179). La influencia de las referencias geográficas bíblicas determinó la existencia de teorías que identificaban a la tierra con elementos como el tabernáculo de Moisés, en el caso de la cosmografía de Cosmas Indicopleustes (siglo VI d. c.); o la representaban en un círculo, a su vez encerrado en un cuadrado, para así concordar con lo que se señalaba en la Biblia: "Y el enviará a sus ángeles con una trompeta sonora para reunir a sus elegidos desde los cuatro ángulos del Universo".

La casi totalidad de las representaciones del Universo eran planas y los cosmógrafos de la época tenían que resolver problemas harto difíciles como el de la ubicación del Paraíso que se suponía debía estar en la zona más elevada del planeta; o la de integrar a la representación plana de la tierra la figura del círculo, símbolo de lo trascedente, de lo perfecto. Es justamente la figuración de la esfera lo que motivó las especulaciones pictóricas de Bosch o las descripciones de Dante en su itinerario a través de un conjunto de círculos concéntricos.

La evolución de la cosmografía durante los siglos XIII al XV manifiesta la profunda preocupación de los especialistas por estructurar una imagen del mundo en correspondencia a una mentalidad que responde a la necesidad de definir un orden vertical, impreso en todas las manifestaciones en la vida en sociedad y una composición circular por los motivos antes expuestos. El "material" para construir esa Imago Mundi estaba constituido por un lado por la existencia de las tierras y los océanos y por otro, por la inevitable presencia del Paraíso, vasto espacio donde convergían la certidumbre geográfica con el rigor de la fe. Además tenía que considerar, a partir de la percepción de las diferencias climáticas y la aceptación de los principios ordenadores señalados, la existencia de dos hemisferios: uno muy conocido y otro poco conocido; en relación al primero las afirmaciones eran incontrastables, mientras que en el segundo las hipótesis tenían terreno fértil. Así, el hemisferio norte se presentaba con trazos y/o palabras firmes y seguras, y el sur con rasgos titubeantes y ambiguos; por suerte para los cosmógrafos, el clima servía de frontera o delimitación zonal y así el mundo tórrido e inhóspito quedaba circunscrito al hemisferio sur mientras que el norte gozaba del beneficio de un clima templado y de la presencia humana.

Fue así que casi todos los mapas se hacían en base a dichos ejes de la construcción cosmográfica y con el Paraíso, referencia infaltable, 
que en una visión Este-Oeste de la tierra se encontraba al oriente, donde comenzaba el mundo, y en una visión Norte-Sur se situaba en el Polo norte, “... en todos los casos el Paraíso era un lugar inaccesible..." (Kappler, 1980 , p. 33$)^{1}$ con barreras que impedían a los hombres tomar contacto con él pero con una naturaleza perfectamente definida y totalmente aceptada. Por el Este salía el sol, por lo tanto el jardín del Edén tenía que localizarse en ese lugar, además, argumento definitivo, en el génesis se señalaba claramente la ubicación oriental del Paraíso. Sea en las descripciones de Isidoro de Sevilla (siglo IV a.c.), en el mapamundi de Hereford (fines del siglo XIII), en la Topografía Cristiana de Indicopleustes, el Paraíso encontró siempre una clara ubicación. También tuvo mucha definición la idea de que el Paraíso estaba en una isla remota en la que vivían los beatos o seres piadosos, esa isla surgía de las aguas del misterioso océano que rodeaba la tierra habitable. El Elíseo de Homero, la Isla de los beatos de Hesíodo o el Jardín de las Hespérides, recordaban desde la antigüedad la imagen del Paraíso a la que el Cristianismo confirmó características definitivas.

Además de los problemas cosmográficos de carácter general, el especialista debía representar, dentro de sus correspondientes espacios, a gentes, naciones y ciudades. Haciendo un balance del mundo conocido, la geografía y aún la topografía europea, no presentaban problemas salvo en las regiones boreales en las cuales la vecindad de un desconocido polo ártico creaba dificultades que fueron superadas con la ayuda de ciertos misioneros irlandeses que permitieron ubicar lejanas islas como las Feroe, las Hébridas e Islandia. Fueron ellas las que permitieron el florecimiento de numerosas referencias legendarias y esas tierras se "reconocieron" hombres que no morían, mujeres que no podían dar a luz o árboles que en vez de frutas daban pájaros (Vigneras, 1976, p. 21). Dentro del conjunto de relatos referidos a ese rincón del mundo, destaca el del viaje de San Brandan, santo irlandés que vivió en el siglo VI al que se le atribuye una peregrinación de varios años por el Atlántico en la que encontró demonios, dragones, buitres y muchas otras manifestaciones maravillosas en las que tomaban parte personajes bíblicos y ángeles. El texto latino de la "Navigatio" de San Brandan fue uno de los "best sellers" de la edad Media (Vigneras, 1976, p. 25), e influyo enormemente en la cartografía relativa a la región atlántica

1 Sobre el paraíso y su presencia en la mentalidad medieval se puede consultar el importante trabajo de Arturo Graf Miti, leggende e superstiziones del Medioevo, publicado en 1892-1893 y reeditado en Milano por Mondadori, 1984. También el Cap. V del libro de Howard R. Pach El otro mundo en la literatura medieval, México, 4 F.C.E., 1983, pp. 142-181. 
nórdica. En todo caso, en relación con Europa, fue el único espacio en que prosperó lo maravilloso. Por otra parte, a inicios del siglo XIII se tenía una idea más o menos clara de Escandinavia gracias a las referencias del historiador y geógrafo danés Saxo Gramático.

Por el sur del continente, las sinuosas costas del Mediterráneo eran perfectamente conocidas y por lo tanto claramente representadas; el norte de África no planteaba problemas gracias a las referencias de los viajeros y geógrafos árabes quienes en sus desplazamientos habían llegado a atravesar el Sahara y entrar en contacto con los misteriosos pueblos negros del trópico; más al sur no existía ningún dato en firme solo sospechas que llevaban a configurar un variable fin de la tierra. El Asia no era desconocida tampoco, el próximo oriente había sido reconocido por cruzados, comerciantes y peregrinos; la India y todas las costas del Océano Indico podían reconstruirse gracias a las escasas referencias de viajeros árabes y cristianos. Más hacia el Este, China (Catay) y Japón (Cipango), mostraban su complejo tejido geográfico gracias a las informaciones de personajes como Marco Polo (siglo XIII), cuya obra no solo acerco a Europa la geografía de las lejanas tierras sino también las costumbres y el aparato instrumental de los pueblos que las habitaban. Hasta mediados del siglo XIV los mapas se enriquecieron con la dinámica de los contactos con el extremo oriente. Pero después de esa época los contactos se interrumpieron debido a la desintegración del Imperio Mongol, que fue el que facilito los desplazamientos en tan enormes espacios. Finalmente, en los extremos septentrionales y meridionales del continente asiático nuevamente triunfaba lo desconocido; por el norte, tierras de frío y oscuridad y por el sur una miríada de islas pobladas de seres monstruosos y plena de maravillas.

En resumen, el europeo en torno a los siglos XIII al XV ya había descubierto prácticamente toda Europa, el Medio Oriente y parte del Extremo Oriente; África y el Asia Meridional todavía planteaban problemas. Se tenía la idea de que el Océano Mundial era muy extenso y que rodeaba a los continentes (Samarkin, 1981, p. 187), además se consideraba una ubicación predominante del Paraíso en el Oriente el cual en las representaciones esquemáticas de la tierra generalmente ocupaba la parte superior.

Todo ese conocimiento fue consecuencia de la acción de tres tipos de agentes: los misioneros tales como los irlandeses en el Atlántico o Juan de Monte Corvino en Asia; los diplomáticos, enviados por reyes cristianos 
o soberanos orientales, como Guillermo de Rubruck (1252-56) o Ruy Gonzales de Clavijo (1369-1412); y los comerciantes, como los Polo de Venezia.

Esos viajes no tuvieron el propósito de realizar descubrimientos geográficos; en el caso de los misioneros sus escritos estaban destinados a excitar la devoción de los lectores, mientras que los comerciantes buscaban informar sobre el buen comercio y los diplomáticos satisfacer las necesidades políticas de sus soberanos. Pero, como señala Jean Richard, todos los viajeros fueron conscientes de que su tarea los llevaba a descubrir cosas interesantes desde la perspectiva geográfica (Richard, 1981, p. $212)^{2}$. No se debe olvidar tampoco la influencia de gran cantidad de viajes imaginarios que brotaron al lado de los viajes reales y que contribuyeron a “enriquecer" la geografía de la época.

Desde la perspectiva cartográfica, los datos proporcionados sirvieron para la confección del llamado Atlas Catalán hecho por Abraham Cresques, cartógrafo del Rey de Aragón, en torno a 1381, pieza que se considera la más completa de representación del conocimiento geográfico de fines de la Edad Media (Skelton, 1970, p. 20); también se usaron en la elaboración del importante mapamundi de Fra Mauro, completado en 1459, el primero en llamar Cipango al Japón. Es de notar el gran desarrollo de la cartografía previa a los descubrimientos de Colón, lo cual prueba los esfuerzos por ubicar en mapa los pocos conocimientos que se tenían sobre lejanas tierras ${ }^{3}$. Pero no se debe olvidar que todas esas referencias geográficas y cosmografías eran producto de la inquietud de una élite que las desarrollaba y difundía; la situación adquiría otro contorno en relación con la masa la cual asimilaba los datos e incluso los recreaba, prefiriendo antes que la geografía de lo conocido, aquella de lo desconocido, por ello:

El Occidente, Francia, Alemania, Inglaterra, Italia, era generalmente apenas citado por los vulgarizadores, que lo estimaban demasiado

2 Otro trabajo importante para penetrar en la problemática de los viajeros de esas épocas es José Antonio del BUSTO Los Descubrimientos Geográficos. Lima, Ed. Arica, 1974. Además de la copiosa información y el original esquema de la obra, se debe resaltar que se trata de una reflexión sobre una problemática alejada de los habituales cauces de la investigación nacional.

3 Al respecto cabe resaltar la información que proporciona el Profesor Oswaldo BALDACCI, en su artículo "La Cartonáutica medievale italiana", publicado en las Atti del Convegno Internazionale de Studi Colombiani, Genova, 1974. 
conocido, y era ignorado por la masa del pueblo, que no quería conocer, más allá de su microrregión, más que los países fabulosos o bíblicos que la podían entretener o cuyas maravillas veían representadas en el portal del nártex de Vezalay, en Aulnay o en otros lugares (Delort, 1982, p. 79).

Por otra parte, ayuda a entender el flujo de información que puede llegar a Occidente el conocimiento que actualmente se puede tener de los territorios y ciudades bañadas por las aguas del océano Indico en esos siglos, ya que así cobra vida la realidad histórica de lo "otro" y su posible proyección de ella en Occidente. Mencionamos como ejemplo, el caso del trabajo de Roxani Eleni Margariti "Aden and the Indian Ocean Trade: 150 years in the life of a Medieval Arabian Port", en donde una reconstrucción histórica del desarrollo físico y de la gran actividad comercial de ese puerto, del siglo $\mathrm{X}$ al siglo XIV, que lo convirtió en el mayor almacén de mercadería del sistema comercial que unía el Océano Indico con el Mediterráneo (Margariti, 2007, p. 2), mucho de ese conocimiento se debe a la práctica de la Geniza que era la preservación de material escrito que compartían como costumbre Judíos y Árabes y que hizo que sobreviva material invalorable sobre esa región antes de la llegada de los portugueses. La Geniza de Sanaa y la Geniza de El Cairo permitieron a Margariti, con la descripción de viajeros árabes de época, reconstruir la vida de Aden medieval. Toda esa dinámica comercial repercutía tanto en Egipto como en Venecia y Génova, llegando así, a través de comerciantes y viajeros, las noticias de Aden en el lejano golfo que baña sus costas.

\section{REALIDADES GEOGRAFICAS Y MECANISMOS ONÍRICOS}

Las civilizaciones se asocian a un espacio más o menos definido, al cual se articulan estructuralmente, y a extensas áreas externas cuyo conocimiento depende de las proyecciones materiales y teóricas que cada una de ellas haya podido alcanzar. Al margen de los espacios propios y de los conocidos se presentan también vastos espacios ignotos, todavía inalcanzables materialmente. Aunque ello no impide un cierto conocimiento de carácter intuitivo que puede ser productor de concepciones integrales de carácter físico, de especulaciones teóricas o simplemente de ideas preconcebidas. La presencia de estos espacios, representados ya sea por zonas continentales o masas acuosas, está íntimamente ligada a la evolución de la técnica y del conocimiento científico, generándose por tanto, conforme retrocedemos en el tiempo, un incremento en su extensión 
y presencia proporcional al nivel técnico y científico. El espacio ignoto se constituye en un permanente desafío no solo al bagaje instrumental y teórico de una civilización, sino también a la imaginación colectiva.

Las fluctuaciones de los espacios conocidos frente a los ignotos como producto de los desarrollo técnicos y teóricos, son analizados por la Historia de la Marginalidad, a la que se une la Historia de lo imaginario, en la media en que dichos espacios ignotos generan intentos de explicación que, desbordando los límites de lo natural y conocido, definen formas, figuras y símbolos donde lo fantástico tiene un papel primordial. La historia de las mentalidades también participa del análisis de la problemática, pues las relaciones colectivas frente a lo desconocido están íntimamente ligadas a las ideas fundamentales que se comparten en torno a las relaciones del hombre con la naturaleza.

Frente a los espacios desconocidos, los grupos humanos despliegan una gama de mecanismos de asimilación y compensación que van desde la creación de concepciones integrales del Universo, la tierra, la naturaleza y el hombre, a la definición de reacciones mentales colectivas de inquietud, temor y violencia, plasmadas en elementos fantásticos y sobrenaturales, que en su momento son entendidos como plenamente reales, ya que responden a una necesidad perentoria de objetivar aquello que genera angustia. En esta problemática alimentada por el temor, el desconcierto o la exageración, los viajes constituyen la manifestación más concreta de asimilación y dominio de los espacios sin que por ello dejen de estar influidos por la fantasía.

Una época particularmente sensible a las fluctuaciones de los espacios conocidos es la comprendida entre los siglos XIII y XV, siglos de descubrimiento y exploración, en los cuales el europeo rompe con los márgenes de su mundo conocido y se proyecta a tierras de incertidumbre y ensueño.

Se podría reconocer, como punto de partida, que uno de los factores generadores de tensión es la relación del hombre con los espacios naturales. Tensiones económicas, sociales, políticas y mentales nacen del afán del hombre por conocer y dominar dichos espacios. Son las tensiones mentales las que llaman nuestra atención, pues entre los siglos XIII y XV adquieren caracteres particularmente marcados a través de la definición de una angustia colectiva. Tensiones que se exacerban por el progresivo dominio de los espacios, consecuencia de la ruptura con pequeños y familiares 
mundos conocidos (llámense señorío, monasterio, castillo, etc). A partir del siglo XIII los desarrollos intelectuales, económicos, técnicos y de otro tipo, generan en las estructuras mentales del europeo, situaciones de shock semejantes (valga la comparación) a la producida por el paso del feto del vientre materno al exterior; a un mundo exterior desconocido y por lo tanto violento y agresivo.

En esta situación, el hombre occidental se encuentra en los límites de un "claustro materno" determinado concretamente por el norte con Escandinavia y la lejana Islandia, por el sur por las calientes tierras saharianas y la misteriosa Abash (Abisinia), por el occidente con el mar tenebroso y por el oriente con la Tartaria y otras lejanas tierras infieles. Eran los límites para unos pocos que los conocían o sabían de ellos, mientras que para la inmensa mayoría de la población su mundo era infinitamente más pequeño.

Cuando el "feto" empieza a debatirse, anhelando el traumático contacto con el exterior, los comerciantes, los misioneros y los diplomáticos ejercen una función obstétrica, sin olvidar tampoco a las cruzadas que desde antes habían creado condiciones previas para el proceso que nos ocupa.

Al romper con los límites de su espacio, los europeos se enfrentan a un mundo ambiguo y maravilloso frente al cual se entremezclan curiosidad y angustia. Ocurrió, como señala Le Goff, un transfert en el plano de la geografía y de la civilización, de los complejos psíquicos y de la mentalidad primitiva (Le Goff, 1977, pp. 275-276). El europeo se debatió entre la seducción y la repulsión frente a lo desconocido.

Pero el cordón umbilical que lo unía al claustro materno no se rompió inmediatamente; el europeo del XIII al XV, sentía todavía el cuerpo materno, especialmente en sus desplazamientos horizontales y terrestres, pues “.... aquello que es horizontalidad, la tierra, el suelo natal o el jardín del Edén devuelve a la imagen materna" (Besancon, 1975, p. 46).

El escenario donde se desarrolla todo es la naturaleza; aquella local, propia, privada y conocida; otra exterior, ajena y desconocida. La primera, impactante en los desplazamientos internos al comunicar ciudades, castillos o monasterios, amenazando con pantanos, bosques y montañas (pasillos desagradables pero ineludibles) y la segunda absorbente, dilatada, desconocida e incluso agradable. Sea como fuere, esas intensas relaciones 
con la naturaleza condicionaron una aproximación a lo sobrenatural, a lo maravilloso.

Son precisamente las profundas transformaciones en las estructuras económicas, sociales y mentales las que traumatizaron al hombre y lo impulsaron a buscar refugio en lo sobrenatural; sobrenaturalidad centrada en la fe, que cumple su papel multiplicador en milagros, y también en la naturaleza, que a su vez muestra abundantemente los suyos. Son los milagros de la naturaleza ignota los que crean imágenes y rompen con los límites de un mundo cerrado, esas imágenes, en donde lo sobrenatural y lo natural se funden, entran a formar parte de una Cristiandad palpitante que se debate dentro de reducidas fronteras, que necesita de una "oxigenación" espacial y mental, y no es ajena a una necesidad de reencuentro con su propia imagen, aunque sea en un mundo al revés representado por el arquetipo onírico y mítico de los antípodas (Le Goff, 1977, p. 273).

Así, los espacios ignotos se vuelven depositarios de mitos y leyendas, de sueños y frustraciones; todo ello enriquecido por una atención y credulidad propias del hombre de la época. No se trata que esos hombres no pudieran distinguir lo imaginario de lo real, lo que sucedía era que no tenían la desconfianza que el hombre contemporáneo tiene de aquello que no ha visto y no planteaban la asociación que hoy se define entre la realidad y materia; ellos usaban otros medios para convalidar la realidad y tenían de ella una valoración distinta (Erickson, 1982, p.15.).

Dos elementos destacan dentro del conjunto de manifestaciones que afloran en la ruptura de los límites de lo conocido: la naturaleza fantástica y la humanidad fantástica. La naturaleza se expresa en términos de flora y fauna y la humanidad a través de expresiones parciales o síntesis asombrosas de lo humano con otras expresiones naturales; todos los fenómenos que forman parte del mundo fantástico adquieren un carácter monstruoso y para el hombre medieval lo monstruoso es “...'una anomalía normal', un avatar necesario, inevitable, testimonio misterioso mas no dramático de la imaginación y de la creación divina" (Kappler, 1980, p.116).

Esos elementos monstruosos, entendidos como "anomalías normales", van a poblar y adornar los espacios desconocidos o poco conocidos. Dentro de la humanidad monstruosa se pueden ubicar seres que expresan características totalmente opuestas a las normalmente atribuidas al hombre por ejemplo, hombres que habitaban en el interior 
de la tierra; seres a los que les falta algún elemento corporal fundamental como los BLEMMYES, hombres sin cabeza; seres que tienen hipertrofia o multiplicación de órganos o miembros como los SCIOPODES, de un solo pie o los bicéfalos: seres de gran tamaño (gigantes) o pequeño tamaño (enanos); seres que presentan una mezcla de sexos como los andróginos o formas híbridas que vinculan lo humano con lo animal. También se puede advertir formas humanas de carácter destructor como los antropófagos o incluso, según las descripciones del viajero Pian Carpin, los tártaros. Esta humanidad fantástica no se origina en todas sus expresiones, al interior de la época analizada, sus orígenes, en algunos casos, se remontan a la Antigüedad a través de expresiones como la del gigante Polifemo.

La fauna también asume varios de los elementos referidos siendo el tamaño la manifestación predominante: ratas, tortugas o perros gigantes y también animales míticos como el Ave Roc. Las anomalías físicas o anatómicas también se expresan en la fauna fantástica, por ejemplo pollos cubiertos de lana. Las figuras de híbridos entre animal y hombre son numerosas: minotauros y cinocéfalos son los más conocidos, no quedando atrás las sirenas o las mujeres serpientes. Extrañas comunidades de animales también pueblan las tierras lejanas, en especial de monos que, según algunos, semejan a hombres o, según otros, hombres que semejan monos; en todo caso para el hombre medieval era difícil trazar una frontera neta entre el hombre y el mono (Kappler, 1980, p. 161).

El reino vegetal también plantea expresiones monstruosas y fantásticas, árboles gigantes, plantas carnívoras, árboles del Mal, árboles que hablan, se unen a formas híbridas de hombre y vegetal como la Mandrágora. Finalmente, en el reino mineral también se pueden encontrar algunas manifestaciones a través de la existencia de piedras raras o fabulosas.

Frente a la riqueza de expresiones de lo monstruoso y maravilloso se debe tener en cuenta que: "Los confines de la realidad tendían a abrazar y a menudo localizar aquello que no se veía y porque determinaba todo, la percepción era considerada un recíproco punto de vista que hallaba en las verdades religiosas la lógica extrema de la existencia”( Erickson, 1982, p.34).

$4 \quad$ Puede ser útil, para llegar a la comprensión y aún la visualización de algunas de las expresiones de la fauna fantástica, la revisión de la obra de Jorge Luis BORGES "Manual de Zoología fantástica". México, Fondo de Cultura Económica, 1980. 
Por otra parte, dos factores alimentaron el detalle y la forma en esas expresiones de lo monstruoso y maravilloso: la antigüedad clásica y el Oriente; en relación a este último espacio estuvieron y estaban ligados en esa época al Islam, pero el otro gran espacio que recién conocían, eran China e India. Baltrusaitis explora esos contactos e influencias y llega a descubrir profusión de elementos fantásticos en la época que nos ocupa y observa como la exploración de Asia, “...la más bella y excitante aventura que pueda imaginarse..." (Baltrusaitis, 1983, p. 177) ${ }^{5}$, deja una herencia de formas e imágenes en la Iconografía Occidental, desde los tocados de las damas hasta los dragones, por ello llega a afirmar que occidente reencuentra a los monstruos gracias a los viajeros que se desplazan por esa geografía desconocida.

\section{LAS MÚLTIPLES CARAS DEL TEMOR}

Los vastos espacios poco conocidos o desconocidos se convierten en terreno fértil para la presencia de una naturaleza y una "humanidad" fantástica. Las expresiones, según se ha señalado, tuvieron sus orígenes en diversos factores: algunos provenientes de la Antigüedad; y otros como resultado de las angustias y temores consecuencia natural del enfrentamiento a lo desconocido; o como efecto de la presencia de mecanismos de compensación ante las presiones de las nuevas condiciones que imponían los cambios estructurales de esa época. Colocando al margen las presencias modélicas provenientes de la Antigüedad griega o romana, conviene explorar los mecanismos de objetivación de los temores en el dominio del espacio, sea en relación con el miedo a lo desconocido o con los mecanismos de compensación derivados de las transformaciones que planteaban las estructuras de las épocas.

Desde esa perspectiva, el siglo XIII es un punto de partida fundamental, las expresiones de una dinámica urbana, el renacimiento comercial y la expansión intelectual dan el marco correspondiente al proceso de construcción de cosmografías, mapas y diversas representaciones de la realidad natural y al modelaje de una nueva mentalidad. Así, se explica también la presencia de esos comerciantes, diplomáticos y misioneros

5 El trabajo del autor es fundamental para la comprensión de las múltiples manifestaciones del arte de la época en su relación con lo fantástico a través de una selección iconográfica importante. También puede consultarse la obra de GAIGNEBET Y LAJOUX “Art profane et religión populaire au Moyen Age". Paris, P.U.F., 1985. 
que contribuyeron a la ampliación del espacio conocido. Pero toda esa actividad alimentaba a su vez angustias y temores que sobretensionaban las condiciones naturales que imponía el enfrentamiento a lo desconocido. En otras palabras, la proliferación de manifestaciones maravillosas y los mecanismos oníricos colectivos referidos a tierras de ensueño, jardines del Edén o de las Delicias, eran consecuencias también de las contradicciones al interior de las diferentes estructuras feudales y de la emergencia de las estructuras propias de un nuevo sistema: el capitalista.

En el entendimiento de que la angustia es índice de un desequilibrio en la armonía de conjunto de las funciones intra - psíquicas y una réplica frente a estímulos ambientales, no es difícil detectar manifestaciones de angustia colectiva frente a los profundos cambios que plantea la sociedad europeo-occidental entre los siglos XIII y XV. Como señala Diel, la angustia es un estado de inquietud que no se siente frente al peligro real sino frente a su posibilidad; lo que desencadena el temor está en el presente, la amenaza que provoca la angustia está en el presente o el pasado (Diel, 1966, p. 175). Así la angustia tomo cuerpo; una angustia que implicaba inquietud ansiedad y melancolía, que provenía de lo desconocido y paradójicamente empujaba hacia él; angustia diversa del miedo que lleva al terror y que es producto de lo conocido. Relacionada con la angustia y el temor está la imaginación; ella llena vacíos y compensa inquietudes siendo su función natural la de ser un mecanismo de previsión de carácter positivo. Así, las nuevas tierras eran enfrentadas con un bagaje de elementos de referencia que pretendían quitar la dosis de temor y hacer más factible la asimilación de lo nuevo.

Las formas y rasgos que asume el contacto o la especulación en torno a los nuevos espacios no llevan a la definición de una exaltación imaginativa, aunque la profusión de elementos puede llevar a entenderlo así: tampoco llevan a la definición de una imaginación de evasión como aquella que podemos encontrar asociada a ciertos grupos de privilegio en una estructura social sujeta a contradicciones, por ejemplo, la aristocracia feudal y sus ideales caballerescos; al contrario, se podría afirmar que se trata de una imaginación de integración que asume en su diálogo con la realidad, una total identificación con ella o una forma de ensueño o mecanismo onírico. Observamos así en la proliferación de manifestaciones naturales y humanas asociadas a los vastos espacios, por un lado, una función de compensación no solo frente al espacio desconocido sino también frente al entorno en transformación; y por otro lado, una función 
de complementación al integrar realidad e imaginación a través de una serie de mecanismos oníricos. Por otra parte, tampoco hay que perder de vista que todo lo nuevo, que en nuestro tiempo atrae, en esa época daba temor.

Tratándose de temores, angustias y mecanismos oníricos, existen factores objetivantes que de alguna manera van a integrar las numerosas expresiones asociadas a los espacios desconocidos; como refiere Delumeau: "Porque es imposible conservar un equilibrio interno y afrontar por largo tiempo una angustia flotante, infinita e indescifrable, es necesario para el hombre transformarla y fragmentarla en temores concretos" (Delumeau, 1978, p. 31).

Dichos factores objetivantes pueden ser lo monstruoso, lo maravilloso y lo pecaminoso. Entre esos elementos tipificadores no existe una división neta, al contrario, algunas manifestaciones reúnen las tres características pero aun así, constituyen una manera de ordenar la difusa presencia de indicadores.

Lo monstruoso: si bien no existe una definición de monstruo se puede considerar monstruoso a todo lo diferente, a todo aquello que evidencia un alejamiento de la naturaleza respecto a lo habitual. En la época que nos ocupa, influyó en la consideración de los monstruoso la Antigüedad y a partir del siglo XIII, muy especialmente, las imágenes de lo monstruoso en la China. Lo monstruoso es recogido por diferentes tipos de fuentes desde la cartografía hasta textos literarios. Pero es importante precisar que el monstruo es entendido como creación y manifestación divina y como tal no puede ser considerado producto del error o del azar. Por consiguiente, lo monstruoso se integra coherentemente dentro del mundo y la mentalidad del hombre de la época, aun cuando sea ligado al desorden o a la fealdad. Como señala Kappler, la noción de monstruo es producto de una convención que sirve para designar a un conjunto de seres en relación a otro que es escogido arbitrariamente por el hombre y que es él el que finalmente organiza las relaciones entre los seres y las cosas (Kappler, 1980, p. 232.). Hasta fines del siglo XV, la "existencia" de los monstruos está integrada a la visión que tiene el europeo del universo; después de esa época hay una mayor tendencia a usar lo monstruoso en diversos sentidos: políticos, religiosos, moralizantes, etc. El final de la Edad Media muestra una conversión progresiva de lo monstruoso en lo diabólico (Kappler, 1980, p. 245), opinando algunos autores que eso fue producto del "contacto" con los monstruos orientales de carácter diabólico, 
a partir del siglo XIII, y como consecuencia de los viajes y el comercio con oriente.

Finalmente no se puede olvidar que el monstruo es también un mecanismo de proyección de fantasmas e inquietudes (¿un sueño?) y es una forma de recrear la realidad o de conocerla en facetas desconocidas, constituyéndose por ello en un tema importante en el Psicoanálisis ${ }^{6}$. La imaginación formula el monstruo pero son el lenguaje y la imagen los que los crean, sin ellos el monstruo se limita a ser un mecanismo onírico volátil e individual. Pero tanto imagen como lenguaje se necesitan mutuamente para la definición del monstruo, un elemento no puede concretar nada sin el otro; es por ello que el hombre de la época no sólo se esfuerza en la descripción literal sino también lo plasma en imagen a tal punto que llena con ellas cartas geográficas, libros, edificios y otros objetos.

Lo maravilloso: durante el Medioevo era muy usado el término "mirabilis", con un significado similar al que hoy tiene y referido a una colección de elementos que los hombres de esa época referían haber visto o haber escuchado decir a otros que habían recibido información al respecto. Al inicio del Medioevo no era común la presencia de referencias relativas a las "mirabilia", los documentos reflejan una represión ejercida probablemente por la Iglesia en tanto expresiones de una cultura pagana. En cambio desde fines del siglo XII encontramos lo que Le Goff llama "la irrupción de lo maravilloso" ( Le Goff, 1983, p. 8.), que encuentra expresión en la caballería, forma de comportamiento e ideal de vida que asume la aristocracia; frente a ello la iglesia cambia de actitud y asume las "mirabilia" definiendo así la naturaleza de mecanismo de evasión que tiene la caballería y su carga de "mirabilis" para un grupo de privilegio que empieza a perder poder y enfrentar a un conjunto de contradicciones al interior de las diferentes estructuras del sistema. Finalmente dentro de contextos cada vez más literarios e intelectuales, los inicios de la modernidad traen consigo una estetización de lo maravilloso.

6 Freud, al desarrollar el proceso de elaboración onírica en su obra "La interpretación de los sueños", proporciona elementos que pueden permitir una aproximación a la naturaleza de lo monstruoso y en general, a las múltiples manifestaciones del temor, que encuentran en el sueño un vasto campo de expresión. Las nociones de condensación, desplazamiento y aquellas relativas a las formaciones mixtas, pueden ser relacionadas a los aspectos que se vienen desarrollando aun cuando su carácter colectivo les defina otras dimensiones. 
Lo maravilloso tiene una función de compensación y es el contrapeso a lo cotidiano (Ibíd., p. 12), por lo tanto tiende a asociarse a ciertos temas básicos como la abundancia de alimentos, la desnudez, el sexo y el ocio, elementos que compensan la escasez, las represiones morales y religiosas y la cotidiana lucha por el mantenimiento de los privilegios, en el caso de las minorías privilegiadas y la lucha por la supervivencia, en el de las mayorías sometidas. Es por eso que a través de manifestaciones naturales se transparentan estas inquietudes básicas: así los seres desnudos que pueblan lejanas tierras hablan de un mundo al revés, como también lo manifiesta la misma imagen del paraíso en la tierra, lugar en el cual no existe el dolor cotidiano. Es por ello que detrás de todas esas expresiones maravillosas subyace la realidad del hombre, sus angustias y necesidades; son consecuencia de expresiones llegadas del inconsciente colectivo, fantasmas que dan lugar al nacimiento de composiciones extrañas que escapan a toda explicación llegando incluso a convertir a lo maravilloso en fantasmagórico (Poiron, 1982, p. 89.). Por todo ello, como refiere Le Goff, “... lo maravilloso deviene en un conjunto de mecanismos oníricos estabilizadores de la psique colectiva y a la vez una forma de resistencia a la ideología oficial del cristianismo" (Le Goff, p.12).

La desintegración de lo maravilloso fue consecuencia de la acción de tres agentes: la misma Iglesia que lo canaliza al milagro, la ciencia que arrincona progresivamente las "mirabilia" o las pone en duda y, finalmente la historia, que desde el siglo XV muestra una apetencia del dato y precisión del momento, que el carácter vago y atemporal de lo maravilloso no puede proporcionar.

Lo maravilloso se compromete activamente con el hombre de la época y asume diferentes manifestaciones. Al respecto Tzvetan Todorov plantea una tipología que hemos visto producida, en su mayor parte, en los elementos descritos anteriormente señala la existencia de un maravilloso hiperbólico (p. e. gigantes); un maravilloso exótico, referido a lo sobrenatural que no admite duda para el hombre de la época (p. e. los blemmyes o el ave roc); lo maravilloso instrumental (p. e. plantas que curan, objetos animados) y lo maravilloso científico, que si bien difícilmente se relaciona con los espacios desconocidos no lo dejamos de reconocer en el elixir de la juventud o en la piedra filosofal (Todorov, 1981, pp. 46 - 47.).

Lo pecaminoso plantea una relación especial con el espacio, asociándose a ciertas formas diabólicas que están presentes dentro del vasto pano- 
rama de creaciones al contacto de los espacios desconocidos. Ciertos elementos vinculados a lo monstruoso no encuentran otra explicación que la ira divina, resultado de un castigo por pecados cometidos. También se tiene que considerar al respecto, la existencia de pueblos en rincones extremos en la tierra, castigados con el aislamiento como Gog y Magog o la presencia cada vez más familiar de los demonios y brujos. El mismo diablo es un monstruo por lo que no nos debe asombrar su presencia en descripciones de viaje o reproducciones de cartas geográficas. Esa atmosfera de satanismo está íntimamente ligada a lo pecaminoso y se desarrolla cada vez más cuanto más nos acercamos al límite cronológico que nos hemos fijado, vale decir el siglo XV.

A pesar de que los monstruos diabólicos de los siglos XIII y XIV parecen manifestar características cómicas o placidas, están como señala Kappler, relacionados con el mal y son de una manera u otra, el fruto del pecado (Kappler, p. 253).

Otro factor ligado a lo pecaminoso es el mar; ya Delumeau, al analizar los aspectos que rodean el temor al mar, descubrió múltiples aspectos a través de los cuales se asocia lo pecaminoso al mar, llamado el "reverso del mundo", destacando entre ellos el caso de la tempestad. "Profundizando el análisis se descubre que el mar, en el pasado, era comúnmente representado como el dominio privilegiado de Satanás y de las potencias infernales" (Delumeau, Jean, p. 59).

Se asocia también a este tipo de objetivación el nacimiento de la idea del purgatorio. Espacio de penitencia y renovación que se define a fines del siglo XII y que se halla ligado a la efervescencia de formas e imágenes asociadas a los espacios, materia de nuestra reflexión. No se trata de una simple coincidencia; en un momento en que "la caza al pecado" se inscribe dentro de una interiorización y una personalización de la vía moral que reclama nuevas prácticas penitenciales (Le Goff, 1981, p. 290), surge la necesidad de ubicar ese espacio purificador y definir los mecanismos conducentes a la liberación del pecado; para ello se debe recordar que en 1215 se introduce el camino de la confesión, examen de conciencia impuesto a los cristianos. Con el nacimiento del purgatorio surge una nueva actitud frente al tiempo y al espacio; al lado de la transformación de la cartografía imaginaria del más allá, se transforma también la cartografía terrestre, ambos procesos se desarrollan al mismo tiempo, en el segundo caso por la acción de viajes misioneros, diplomáticos o comerciantes y en el primer caso por la acción de los teólogos. 


\section{DESPLIEGUE Y REPLIEGUE DEL TEMOR Y DE LOS SUEÑOS}

Los sueños y los temores, lo conocido y lo desconocido, la geografía y las maravillas, todo ello necesitaba un espacio concreto donde se concentraran y expresaran sus inquietudes; este espacio fue inicialmente el Océano Indico, espacio fluctuante de inciertos límites, conocido de unos pocos y privilegiados cristianos.

Ubicado el reino de lo sobrenatural y maravilloso, se busca domesticar y moralizar ese Océano, convirtiendo a pigmeos en símbolo de humildad, a gigantes en símbolo de orgullo y a cinocéfalos en símbolo de belicosidad; se trata de incorporar todo al mundo natural y divino, aún a costa de alegorías. Aunque subsistía también la perspectiva que hacía del Indico un mundo anti-natura, escandaloso y por lo tanto extraño al hombre. Como señala Le Goff: "En las dos perspectivas el Océano Indico es un horizonte mental, lo exótico del Occidente Medieval, el lugar de sus sueños y de la liberación de sus inhibiciones. Explorarlo significa reconocer una dimensión esencial de su mentalidad y de su sensibilidad"7.

El Indico se vuelve el mundo prohibido en el cual todo lo imaginario se vuelve real y lo real se vuelve imaginario; allí se incuban malos deseos y protervas inclinaciones, el incesto, la poligamia, el canibalismo y las más extrañas manifestaciones del sexo. Todos los tabúes se vienen abajo, lo más extraño se vuelve realidad, una realidad que respira libertad, un lugar donde se puede hacer lo que se desea y por lo tanto un lugar feliz: un Paraíso. En buena cuenta el europeo proyecta todos sus fantasmas, ansiedades y necesidades en ese horizonte onírico. (Schmitt, p. 348).

Se observa que el Paraíso está ligado al Índico y posee una imagen con una doble perspectiva: por un lado, paraíso de riquezas y bienestar sensorial, y por otro, paraíso espiritual e inocente. Ambas consideraciones funcionan para el hombre medieval sin oponerse, pues se trata de un paraíso en la tierra, en él paradójicamente lo bueno y lo malo se confunden y el hombre se remonta hasta antes del pecado original y el cristianismo.

7 LE GOFF, Jacques. L'Occidente medievale e 1'Oceano Indiano: un orizzonte onírico. Conviene señalar que el artículo citado fue ponencia en el $6^{\circ}$ Coloquio Internacional de Historia Marítima, Venezia, 1962; las actas de la reunión fueron publicadas bajo el título "Mediterranée et Océan Indien" París, S.E.V.P.E.N., 1970. En esa obra se pueden encontrar importantes estudios relativos a la vinculación entre los dos espacios desde la época romana hasta el siglo XX. 
Al principio solo pequeñas rendijas geográficas permitían vislumbrar ese mundo de ensueño y fantasía donde se proyectaban las necesidades, traumas y frustraciones del europeo. Las llamadas "islas felices y opulentas" seguían siendo el lugar en que "...el Occidente escapa a la realidad mediocre de su fauna y reencuentra la inacabable imaginación creadora de la naturaleza y de Dios" (Le Goff, p. 270). Y no solo la fauna mediocre, sino también una mediocre vida cotidiana que ya contrasta con los profundos remezones del aparato espiritual y material al contacto con la dinámica de las intensas transformaciones de su tiempo.

Mientras esas ventanas están entreabiertas, los sueños se conservan y enriquecen, pero cuando se abren totalmente, se esfuman. La progresiva excursión europea en el Indico se encargó de despejar las brumas que velaban ese horizonte onírico, alejando cada vez más el anhelado paraíso, hasta la violación traumática del viaje de Vasco da Gama (1498-1499).

La multiplicación de las intenciones profanadoras y el repliegue de la visión paradisiaca, son pruebas de las nuevas inquietudes de los europeos. Se vislumbra cada vez con mayor claridad, el deseo de descubrir, de dominar los espacios y de rechazar el caos; aún a costa de alejar a su paraíso y de acabar con sus sueños. Es justamente esa actitud decidida y ordenadora la que revivifica el miedo; un miedo presente pero aletargado en el Paraíso Indico un miedo "respetuoso" a la majestad de los divino y fantástico y no un miedo que nace del desafío agresivo a lo desconocido. Aunque la exacta determinación cronológica es imposible, son los años del siglo XV los que contemplan estos cambios progresivos, años donde el paradisiaco Océano Indico se enfrenta a la competencia del tenebroso Océano Atlántico y donde los miedos se exacerban.

Efectivamente, conforme vamos llegando a los últimos años del siglo XV y principios del XVI vemos cómo se va imponiendo la determinación de extender el Imperio del hombre. Este proceso debemos entenderlo, entre otras cosas, como consecuencia y manifestación de una época afectada por la disolución de los niveles de fe y conocimiento. En ese contexto el control de los espacios surgía como un antídoto al desorden imperante (Rabb, 1975, p. 53). Fue así como los sueños intocados e intocables dejaron de serlo, quedando los velos rasgados que los separaban del horizonte onírico Indico, como prueba de ello, se trató, a partir de ese momento, de dominar y de conquistar, de sacralizar la naturaleza, al decir de M. Eliade. 
Pero no debemos sobrevalorar la fuerza y la madurez del europeo de esos años, pues la credulidad todavía participaba de un ser y de su relación con la naturaleza. Al tratar de comprenderlo recordemos a Febvre, quien afirmaba que:

(...) nosotros somos hombres de invernadero, ellos lo fueron de aire libre. Hombres cercanos a la tierra y al vivir rural, hombres que aún dentro de sus ciudades encontraban el campo, la ruralía, con sus animales, sus plantas, sus olores y sus ruidos. Hombres de aire libre, que veían y sentían, olían y aspiraban la naturaleza por todos sus sentidos y poros. (Febvre, 1959, p. 369).

Ante esta situación, no nos debe asombrar que el miedo visite al hombre que intente dominar el espacio y por ende la naturaleza. Es la rebelión del infante convertido en adolescente, con su dosis de razón y de audacia, de miedo y angustia.

El hombre del Renacimiento, soberbio en su individualismo y práctico en sus actos, siente la necesidad de divisar el espacio con nuevos ojos; aprecia la fertilidad o riqueza más que la belleza o fealdad, refleja tintes impresos por la exaltación del capitalismo mercantil. Busca definir los límites naturales, pues al hacerlo siente que se define a sí mismo. Lo vemos alejarse lentamente de las incertidumbres e imprecisiones de los espacios, a través de la definición de fronteras nacionales, económicas y espirituales plasmadas en los estados, los intercambios y las Iglesias nacionales. Camino largo y penoso que se terminará de recorrer recién en el siglo $\mathrm{XX}$.

En esa inquietud el miedo se acentúa; se mezcla miedo con fracaso, con la imagen de sus limitaciones e impotencia contrastante con la exaltación del Humanismo, con el miedo natural por lo desconocido. Y si en el horizonte Índico el miedo era postergado por imágenes placenteras de riquezas y paraísos, en el horizonte Atlántico se sobreponía a ellas. Miedo permanente asociado al mar, las estrellas, las apariciones, no miedo cíclico como la peste, la guerra. Miedo objetivado a una forma fantástica brutal y violenta, no solo extrañamente sobrenatural.

Las concepciones físicas del universo no lo ayudan en este caso, el abierto Atlántico lo aproxima al fin de la tierra y lo amenaza con esa fauna fantástica, agresiva y horrenda. Los barcos se pierden al contacto con el océano y el viaje deja de ser una excursión en busca del paraíso para 
convertirse en un giro en torno a la muerte. El miedo hace ver pulpos y calamares gigantescos, serpientes marinas y aves monstruosas; mientras que el agua circundante se torna más amenazante por acción de los elementos. En ese sentido el descubrimiento colombino es fundamental, atravesar el Océano tenebroso implicó triunfar sobre las expresiones más terribles de la naturaleza agresiva. Se fue descorriendo un velo de misterio y casi de horror, no se trataba del maravilloso Indico sino del agresivo Atlántico, aunque ello no significaba que lo maravilloso no estuviera presente en la gesta descubridora porque: "Si Colón habló de "cosas maravillosas" es porque efectivamente las tuvo ante sus ojos en el origen de su vocación descubridora y no podía sustituirlas, ni ante sí ni ante los demás, por otro género de recurso" (Pérez de Tudela, 1983, p. 99) ${ }^{8}$.

Es Colón tributario de las maravillas índicas, gestadas desde el siglo XIII, pero a la vez es el agente de transformación y de sacralización de un espacio en donde lo maravilloso deja de tener las suaves ondulaciones y aristas del ensueño y asume fundamentalmente las violentas fracturas y los accidentados relieves del temor. No en vano se encuentra entre dos siglos y asume los rasgos de una nueva época.

El tránsito de una Cristiandad deslumbrada por tierras plenas de fantasía, bienestar material y espiritual, a una Cristiandad más realista y ansiosa de definir sus límites de fe y riqueza, de espacio y conocimiento, puede comprenderse por analogía al pasaje de la infancia a la adolescencia. En ese contexto es lógico que los procesos de demonización reemplacen paulatinamente a los paraísos imaginarios y las curiosidades naturales se vuelvan extravagancias amenazantes. Por eso, como señala F. Mauro "Pese a la audacia de los marinos y al valor de los soldados, al ideal del héroe del Renacimiento y a su virtud, el sentimiento dominante era el del miedo" (Mauro, 1969, p. 221).

Si solo nos ubicáramos a nivel de los grandes personajes y de las acciones destacadas, se diluiría nuestra comprensión del miedo. El miedo de un Colón o un Cortez quedaría en lo anecdótico, sería nada frente a los sucesos cumplidos. Pero debemos entender que forma parte importante en las estructuras mentales de los hombres de esa época y que se incuba en

8 El libro de Pérez de Tudela constituye un estudio sistemático y crítico del origen y significado del proyecto descubridor de Colón; recoge las manifestaciones de las "mirabilia" condicionantes. 
las raíces mismas de sus vidas y en sus proyecciones a la muerte. Miedo a la vida por ser negación de la belleza y la dicha y porque significa dolor y tormento (Huizinga, 1965, p. 257); y miedo a la muerte por la incertidumbre de lo desconocido.

Son miedos de principio y de fin, pero también miedos intermedios como el miedo a la oscuridad que ponía un límite a la contemplación de la naturaleza. No nos asombre entonces, el miedo al Atlántico, océano tenebroso, en oposición al Índico, pleno de destellos y refulgente de riqueza. Miedo incubado y predispuesto por una subalimentación en donde la falta de una dieta suficiente desencadenaba la imaginación y las pesadillas y llevaba al pánico. Largas y oscuras noches, estómagos vacíos y agresiones climáticas acrecentaban los problemas y conducían a la violencia; allí en ese contexto, el miedo fructificaba.

Esa clara inclinación a la violencia presente en todas las esferas sociales, en las actividades económicas y en las relaciones con la naturaleza, servía de combustible al miedo. (Hale, 1973, p.25) Se lucha contra el hombre, contra la naturaleza y contra sí mismo; con miedo pero por necesidad, necesidad económica, social y más aún mental. Probar las fuerzas, probarse a sí mismo, canalizar las angustias y violentar a la Naturaleza desafiante, son algunas de las vivencias que agitan al hombre de esa época.

La superación de esos miedos y la canalización de esa violencia fueron las que posibilitaron el progresivo dominio de los espacios. Los continentes fueron reconocidos y las zonas ignotas se refugiaron en los rincones más apartados de la tierra, quedando al final una especie de frustración y nostalgia que el hombre del siglo XX intenta disipar en la búsqueda del dominio de los espacios extraterrestres. Quizá en las mismas condiciones que se tuvieron en el otoño de la Edad Media.

\section{REFLEXIONES FINALES}

Como se ha señalado, el miedo y el ensueño en el dominio del espacio no desaparecen al llegar el siglo XVI, subsisten incluso al interior de la estructura mental del hombre contemporáneo. El estudio del caso que nos ocupa, constituye una expresión de la larga duración de los elementos integrantes de la mentalidad colectiva y de la complejidad que ella plantea. Esa naturaleza compleja y particular obliga a un análisis conjunto por 
parte de psicólogos e historiadores. Como señala Duby, al analizar los contenidos impersonales del pensamiento, no puede existir historia de las mentalidades sino como fruto de un trabajo colectivo (Duby, 1976, p. 253).

Es por eso que los ensueños y miedos ligados al dominio del espacio subsisten en los buscadores de "El Dorado" en el siglo XVI; toman nuevas manifestaciones a raíz de los viajes de Cook o La Condamine; se desdibujan en los esfuerzos de un Amundsen o un Peary y adquieren nuevos contornos en las inmersiones de un Piccard o en la experiencia lunar de 1969. Es siempre miedo, pero con una dosis cada vez menor de ensueño debido a los cambios que impone el desarrollo continuo del aparato tecnológico.

En conclusión, si las ideas expuestas desde una perspectiva histórica despiertan interés en psicólogos y psiquiatras por abordar la llamada psicohistoria, se habrá cumplido nuestro cometido; así como lo sentimos cumplido al habernos aproximado en nuestro esfuerzo a la historia total: una historia del hombre en sociedad, vista y comprendida desde todas sus perspectivas y considerando las interacciones de todos sus componentes, en su dinámica múltiple y a lo largo de sus procesos. Todo ello se ha formulado con la convicción fundamental de que todas las Ciencias Humanas pueden hablar el mismo idioma.

\section{REFERENCIAS BIBLIOGRÁFICAS}

ALPERS, Edward

2014 The Indians Ocean in World History. New York: Oxford University Press.

ARIES, Philippe

1978 "L'histoire des mentalités". En: La Nouvelle Histoire. Paris: Retz.

A.A. V.V.

1970 Sixieme Colloque D'Histoire Maritime. Méditerranée et Océan Indien. Paris: S.E.V.P.E.N.

BALDACCI, Oswaldo

1974 "La cartonautica medievale italiana". En: Atti del convegno internazionale de Estudi Colombiani. Génova. 
BALTRUSAITIS, Jurgis

1983 La Edad Media fantástica. Madrid: Catedra.

BESANCON, Alain

1975 Storia e Psicoanalisi. Napoli: Guida Edit.

BOORSTIN, Daniel

1986 Los descubridores. Barcelona: Edit. Crítica.

BORGES, Jorge Luis

1980 Manual de zoología fantástica. México: Fondo de Cultura Económica. BUSTO, José Antonio del

1974 Historia de los descubrimientos geográficos. Lima: Edit. Arica.

CERTAU, Michel de

1978 "Histoire et Psychanalyse". En: La Nouvelle Histoire. París: Retz.

CHAUNU, Pierre

1972 La expansión europea. Barcelona: Edit. Labor.

DELORT, Robert

1982 La vie au Moyen Age. Paris: Seuil.

DELUMEAU, Jean

1978 La peur en Occident. Paris: Fayard.

DIEL, Paul

1966 El miedo y la angustia. México: Fondo de Cultura Económica.

DUBY, Georges

1976 "La Edad Media". En: La Historia Hoy. Barcelona: Ed. Avance.

ERICKSON, Caroly

1982 La visione del Medioevo. Napoli: Liguori Ed.

FEBVRE, Lucien

1959 El problema de la incredulidad en el siglo XVI. México: UTEHA. 
FREUD, Sigmund

V.V. Edics. La interpretación de los sueños. Madrid: Alianza Editorial.

FRIEDLANDLER, Saul

1975 Historie et Psychanalyse. Paris: Editions du Seuil.

GAIGNEBET, Claude et LAJOUX, J.D.

1985 Art. profane et religion populaire au Moyen Age. Paris: P.U.F.

HALE, J.R.

1973 La Europa del Renacimiento. Madrid: siglo XXI.

HUIZINGA, Johan

1965 El otoño de la Edad Media. Madrid: Rev. De Occidente.

KAPPLER, Claude

1980 Monstres, démons et merveilles á la fin du Moyen Age. Paris: Payot.

LE GOFF, Jacques

1983 Il meraviglioso e il quotidiano nell'Occidente medievale. Bari: Editori Laterza.

1982 La naissance du Purgatoire. Cher: Editions Gallimard.

1977 "L'Occidente medieval e 1'Oceano Indiano: un orizzonte onírico". En: Tempo de la Chiesa e tempo del mercante. Torino: Einaudi Edit.

1971 La Baja Edad Media. Madrid: Siglo XXI.

MARGARITI, Roxani Eleni

2007 Aden in the Indian Ocean Trade: 150 year in the life medieval arabian port North Carolina: North Carolina Press.

MAURO, Frederic

1969 Europa en el siglo XVI. Barcelona: Labor.

NEWTON, Arthur Percival

1930 Travel and Travellers of the Middle Ages. London: Kegan Paul

NORA, Pierre y LE GOFF, Jacques

1980 Hacer la historia. Barcelona: Edit. Laia. 
PEREZ DE TUDELA, Juan

1983 Mirabilis Altis. Madrid: C.S.I.C.

POIRON, Daniel

1982 Le marveilleux dans la litterature francaise du Moyen Age. Paris: P.U.F.

RABB, Theodore

1975 The struggle for stability in Early Modern Europe. New York: Oxford Univ. Press.

RICHARD, Jean

1981 "Voyages reels et voyages imaginaires, instruments de la connaissance geographique au Moyen Age". En: Culture et travail intelectuel dans l'Occident Medieval. Paris: CNRS.

SAMARKIN, V.

1981 Geografía histórica de Europa Occidental en la Edad Media. Madrid: Akal.

SCHMITT, Jean Claude

1978 "L'histoire des marginaux". En: La Nouvelle Histoire. Paris: Retz.

SKELTON, R.A.

1970 Explorers Maps. Hong Kong: Spring Books.

TODOROV, Tzvetan

1981 Introducción a la literatura fantástica. México: Premia Edit.

VIGNERAS, Luis André

1976 La búsqueda del Paraíso y las legendarias islas del Atlántico. Valladolid: Cuadernos Colombinos.

VOVELLE, Michel

1985 Ideologies et mentalités. Paris: LD/Fondations. 